\title{
АНАЛИЗ ТЕХНИКО-ЭКОНОМИЧЕСКИХ ПОКАЗАТЕЛЕЙ ПРОМЫШЛЕННЫХ РОБОТОВ
}

\author{
Дубинина В.B.
}

В данной статье проведен анализ технико-экономических показателей промышленных роботов для покраски, точечной сварки и паллетирования компаний Kuka, Fanис и Yaskawa Motoman. Для этих роботов построены модели зависимости их цень от грузоподъемности, радиуса действия, точности позиционирования, массы, технического индекса.

DOI: $10.20537 /$ mce2021econ11

Введение. В настоящее время темпы автоматизации ускоряются, промышленные роботы распространяются на предприятиях по всему миру, расширяется список задач и отраслей, в которых они применяются. Кроме того, увеличивается ассортимент и появляются новые типы роботов - от гибких механических конечностей до умных машин, которые могут работать вместе с людьми. С развитием информационных технологий в промышленной робототехнике происходят постоянные изменения, приводящие к новым функциональным решениям и более широким возможностям применения промышленных роботов.

Целью данной работы является построение моделей зависимости цены промышленных роботов (ПР) от таких технических характеристик как грузоподъемность (кг), радиус действия (мм), точность позиционирования (мм), масса (кг), а также технический индекс, рассчитанный как произведение грузоподъемности на радиус действия и отнесенный к массе роботов.

Аналогичные исследования проводились по сервисным роботам, где моделировалась зависимость цены от технических показателей для медицинских, персональных роботов и БПЛА [1]; а также по промышленным роботам компаний Fanuc и $\mathrm{ABB}$ большой, средней и малой грузоподъемности [2].

Ведущие компании-производители промышленных роботов. Использование промышленных роботов на производстве расширяется. Возможности ПР постоянно совершенствуются, и они способны выполнять 
более сложные и разнообразные задачи с наибольшей скоростью и точностью. К основным задачам роботов относятся: паллетирование, перемещение и упаковка изделий, сварка, сборка, обработка деталей, покраска.

Так, например, в 2019 г. на долю роботов, выполняющих операции по перемещению, приходилось 42\% (в России - 46\%), сварку и пайку $21 \%$ (27\%), сборку - 10\%, обработку - 1\% (4\%) [3].

В данной работе были рассмотрены ПР для паллетирования компаний Fanuc и Yaskawa Motoman, а также роботы для точечной сварки и покраски компании Kuka.

Роботы компании Yaskawa Motoman используются в автомобильной, аэрокосмической, пищевой, химической промышленности и т.д.; роботы Fanuc — в аэрокосмической, автомобильной промышленности, в отрасли товаров народного потребления и многих других отраслях; роботы компании Kuka - в автомобильной, пищевой и электронной промышленности, для производства пластмасс, в металлообработке и т.д.

Эти компании являются ведущими производителями робототехники в мире. К 2019 г. по всему миру было установлено 500 тыс. роботов компании Fanuc, 400 тыс. ед. — Yaskawa Motoman, 381 тыс. ед. — Kuka (табл. 1).

Таблица 1. Количество установленных ПР за всё время (тыс. ед.). Источник: $[4,5,6]$.

\begin{tabular}{|l|c|c|c|}
\hline \multicolumn{1}{|c|}{ Компании } & $\mathbf{2 0 1 4}$ & $\mathbf{2 0 1 8}$ & $\mathbf{2 0 1 9}$ \\
\hline Fanuc & 250 & 400 & 500 \\
\hline Yaskawa Motoman & 300 & 360 & 400 \\
\hline Kuka & 100 & 350 & 381 \\
\hline
\end{tabular}

Роботы для паллетирования с помощью специального захвата осуществляют подбор продукции с конвейера и укладывают ее на паллеты. Грузоподъемность роботов-паллетайзеров Motoman составляет 50-800 кг, Fanuc - 40-1700 кг.

Роботы-паллетайзеры Motoman используются на заводах Boeing, Audi; Fanuc - для паллетирования изоляционных материалов, компонентов для грузовых автомобилей DAF, на заводах Honda, Audi,Volkswagen, Hyundai, Nissan, Opel и BMW, в пищевой промышленности - укладывают на паллеты сыры, джемы, консервы и другую продукцию в компаниях Nestlé, Unilever, Budweiser, Coca-Cola и др. В компании Hero AG для заполнения коробок с джемом и укладки их на поддоны применяются три робота Fanuc M-710iC. 
Роботизированная точечная сварка является одной из самых востребованных операций на современном производстве. Она характеризуется высокой производительностью при стабильном качестве выполнения работы. Точечная сварка в основном применяется в автомобильной промышленности. Например, роботы Кuka для точечной сварки сваривают держатель приборной панели на заводе Mercedes, кузова для Jeep Wrangler на заводе Toledo, также применяются в металлургической промышленности.

В России сварочные роботы применяются на заводах Volgabus (производство автобусов, используется 29 роботов Kuka), LADA - 13 сварочных робота, АвтоВаз - 6 ед. В 2019 г. КАМАЗ установил 11 сварочных роботов Kuka [7]. На заводах компании «Группа ГАЗ» задействованы более 600 ПР, из которых 100 ед. - роботы Кuka. На сварочных линиях установлено более 90 роботов Fanuc [8].

Покрасочные роботы используются для выполнения широкого круга задач. Например, в автомобильной промышленности - для покраски и нанесения разнообразных покрытий на колесные диски машин, покраски деталей и кузовов автомобилей; в мебельной промышленности они окрашивают изделия, наносят лак на деревянные поверхности, в электронной — красят крышки ноутбуков.

Покрасочные роботы Кuka используются в компаниях Boeing, Hannex, на автомобильных заводах BMW, Ford, Porsche, Mercedes Benz, Audi, Chrysler, Ferrari.

Моделирование зависимости цены промышленных роботов от их технических показателей. Для построения моделей зависимости рассмотрены роботы Кuka для точечной сварки (8 моделей роботов), произведенные в период 2008-2016 гг. и ценой от 16 тыс. долл. до 52 тыс. долл.; покрасочные роботы Kuka 2002-2015 гг. выпуска и ценой 11-78 тыс. долл. (22 ПР); роботы-паллетайзеры Fanuc - произведенные в период 2003-2017 гг. и ценой 10-55 тыс. долл. (20 ПР), Yaskawa Motoman — 2009-2015 гг. выпуска и ценой от 23 тыс. долл. до 51 тыс. долл. (8 ПР).

Для роботов компании Kuka, предназначенных для покраски и точечной сварки, были построены модели зависимости цены от грузоподъемности, технического индекса и года выпуска.

Технический индекс (ТI) рассчитан как отношение произведения грузоподъемности на радиус действия к массе роботов:

$$
\mathrm{TI}=\frac{\text { грузоподъемность } \times \text { радиус действия }}{\text { масса }} .
$$


Анализ и моделирование экономических и сочиильньх процессов - МКО - 2021 Analysis and modeling of economic and social processes - MCE - 2021

Такой выбор технического индекса связан с тем, что развитие ПР направлено на увеличение их грузоподъемности и радиуса действия при снижении массы.

Моделирование зависимости цены ПР от технических показателей проведено на основании данных, приведенных в табл. 2,3.

Таблица 2. Технико-экономические показатели покрасочных роботов Kuka (по данным [9]).

\begin{tabular}{|l|c|c|c|c|c|c|}
\hline Модель робота & год & $\begin{array}{c}\text { цена, } \\
\text { долл. }\end{array}$ & $\begin{array}{c}\text { грузо- } \\
\text { подъем- } \\
\text { ность, } \\
\text { кг }\end{array}$ & $\begin{array}{c}\text { радиус } \\
\text { дей- } \\
\text { ствия, } \\
\text { мм }\end{array}$ & $\begin{array}{c}\text { масса, } \\
\text { кг }\end{array}$ & $\begin{array}{c}\text { точность } \\
\text { позицио- } \\
\text { нирова- } \\
\text { ния, мм }\end{array}$ \\
\hline KR 150 & 2002 & 11809 & 150 & 2700 & 1245 & 0.12 \\
\hline KR 180 & 2006 & 11809 & 180 & 2700 & 1267 & 0.12 \\
\hline KR 210 & 2005 & 11809 & 210 & 2700 & 1267 & 0.12 \\
\hline KR 16 KS-F & 2007 & 13954 & 16 & 1801 & 235 & 0.1 \\
\hline KR 60 L45-3 & 2004 & 13982 & 45 & 2430 & 610 & 0.25 \\
\hline KR 240 & 2008 & 14665 & 240 & 2700 & 1267 & 0.12 \\
\hline KR 16 KS & 2007 & 15035 & 16 & 1801 & 235 & 0.1 \\
\hline KR 30 L16 & 2004 & 16892 & 16 & 3102 & 700 & 0.07 \\
\hline KR 150-2 & 2009 & 17526 & 150 & 2700 & $\ldots$ & $\ldots$ \\
\hline KR 60 L30-3 KS & 2007 & 18520 & 30 & $\ldots$ & 615 & 0.25 \\
\hline KR 360 & 2006 & 18645 & 360 & 2826 & 2350 & 0.15 \\
\hline KR 30-3 & 2011 & 18724 & 30 & 2033 & 665 & 0.15 \\
\hline KR 60-3 F & 2009 & 19764 & 60 & 2041 & 880 & 0.06 \\
\hline KR 360 L240-2 & 2007 & 20882 & 240 & 3300 & $\ldots$ & $\ldots$ \\
\hline KR 5 Arc & 2015 & 21184 & 5 & 1412 & 127 & 0.1 \\
\hline KR 60 & 2010 & 21727 & 60 & 2033 & 635 & 0.2 \\
\hline KR 30-2 & 2003 & 21929 & 30 & 2033 & 865 & 0.15 \\
\hline KR 30 L16-2 & 2015 & 25922 & 16 & 3102 & 700 & 0.07 \\
\hline KR 210-2 F & 2009 & 40737 & 210 & 2700 & 1412 & 0.06 \\
\hline KR 500 L340-3 & 2013 & 49900 & 340 & 3325 & 2411 & $\ldots$ \\
\hline KR 500 & 2008 & 52799 & 500 & 2836 & 2350 & 0.15 \\
\hline KR 500-3 & 2014 & 78338 & 500 & 2826 & 2385 & $\ldots$ \\
\hline & & & & & & \\
\hline
\end{tabular}


Дубинина В.В. Анализ технико-экономических показателей промышленных..., стр. 117-123 Dubinina V.V. Analysis of technical and economic indicators of industrial robots, pp. 117-123

Технические характеристики роботов Kuka для точечной сварки приведены в табл. 3.

Таблица 3. Технико-экономические показатели роботов Kuka для точечной сварки (по данным [9]).

\begin{tabular}{|l|c|c|c|c|c|c|c|}
\hline $\begin{array}{l}\text { Модель } \\
\text { робота }\end{array}$ & $\begin{array}{c}\text { Год } \\
\text { вы- } \\
\text { пуска }\end{array}$ & $\begin{array}{c}\text { Цена, } \\
\text { долл. }\end{array}$ & $\begin{array}{c}\text { Грузо- } \\
\text { поъьм- } \\
\text { ность, кг }\end{array}$ & $\begin{array}{c}\text { Радиус } \\
\text { дей- } \\
\text { ствия, } \\
\text { мм }\end{array}$ & $\begin{array}{c}\text { Точность } \\
\text { позицио- } \\
\text { нирова- } \\
\text { ния, мм }\end{array}$ & $\begin{array}{c}\text { Масса, } \\
\text { кг }\end{array}$ & ТІ \\
\hline $\begin{array}{l}\text { KR 6 } \\
\text { R1820 }\end{array}$ & 2016 & 16602 & 6 & 1820 & 0.04 & 168 & 65.0 \\
\hline $\begin{array}{l}\text { KR 210 } \\
\text { R2700-2 }\end{array}$ & 2008 & 20007 & 210 & 2701 & 0.05 & 1077 & 526.7 \\
\hline $\begin{array}{l}\text { KR 240 } \\
\text { R3330 }\end{array}$ & 2013 & 29517 & 240 & 3326 & 0.08 & 2421 & 329.7 \\
\hline $\begin{array}{l}\text { KR 360 } \\
\text { R2830 }\end{array}$ & 2016 & 36222 & 360 & 2826 & 0.08 & 2385 & 426.6 \\
\hline $\begin{array}{l}\text { KR 150 } \\
\text { R2700-2 }\end{array}$ & 2014 & 37356 & 150 & 2701 & 0.05 & 1072 & 377.9 \\
\hline $\begin{array}{l}\text { KR 10 } \\
\text { R1420 }\end{array}$ & 2016 & 40800 & 10 & 1420 & 0.04 & 160 & 88.8 \\
\hline $\begin{array}{l}\text { KR 280 } \\
\text { R3080 }\end{array}$ & 2015 & 49478 & 280 & 3076 & 0.08 & 2415 & 356.6 \\
\hline $\begin{array}{l}\text { KR 500 } \\
\text { R2830 }\end{array}$ & 2016 & 52799 & 500 & 2826 & 0.08 & 2385 & 592.5 \\
\hline
\end{tabular}

Для перечисленных моделей роботов Кuka были построены зависимости вида:

$$
Y=a_{0}+a_{1} x_{1}+a_{2} x_{2}+b t
$$

где $Y$ - цена или логарифм цены роботов, тыс. долл., $x_{1}$ - грузоподъемность, кг, $x_{2}$ - логарифм технического индекса, $t$ - год выпуска роботов.

Получена положительная корреляция между ценой покрасочных роботов и их грузоподъемностью (модель 1), а также техническим индексом (модель 2), см. табл. 4. При этом цена роботов увеличивается с течением времени.

В модели 3 увеличение технического индекса приводит к большему росту цены по сравнению с покрасочными роботами этой же фирмы (модель 2). Увеличение года выпуска робота для точечной сварки повышает его стоимость в большей степени, чем у покрасочного. 
Технические показатели роботов компаний Fanuc [10] и Yaskawa [11] использованы для получения моделей 4 и 5 (табл. 4). Для обеих компаний получена положительная корреляция между логарифмом цены робота и логарифмом технического индекса.

Таблица 4. Оценки параметров модели (1) для разных типов промышленных роботов Kuka, Fanuc и Yaskawa.

\begin{tabular}{|c|c|c|c|c|c|}
\hline \multirow[t]{2}{*}{$\begin{array}{l}\text { Пара- } \\
\text { метры }\end{array}$} & \multicolumn{2}{|c|}{$\begin{array}{c}\text { Покрасочные роботы } \\
\text { Kuka }\end{array}$} & \multirow{2}{*}{$\begin{array}{c}\begin{array}{c}\text { Роботы для } \\
\text { точечной } \\
\text { сварки Кuka }\end{array} \\
\text { Модель } 3\end{array}$} & \multirow{2}{*}{$\begin{array}{c}\begin{array}{c}\text { Роботы- } \\
\text { паллетай- } \\
\text { зеры Fanuc }\end{array} \\
\text { Модель } 4 \\
\end{array}$} & \multirow{2}{*}{$\begin{array}{c}\text { Роботы-пал- } \\
\text { летайзеры } \\
\text { Yaskawa } \\
\text { Модель } 5 \\
\end{array}$} \\
\hline & Модель 1 & Модель 2 & & & \\
\hline Y & цена & $\begin{array}{c}\text { Логарифм } \\
\text { цены }\end{array}$ & $\begin{array}{c}\text { Логарифм } \\
\text { цены }\end{array}$ & $\begin{array}{c}\text { Логарифм } \\
\text { цены }\end{array}$ & $\begin{array}{c}\text { Логарифм } \\
\text { цены }\end{array}$ \\
\hline $\mathrm{a}_{0}$ & $\begin{array}{c}12770 \\
(3.5)\end{array}$ & $\begin{array}{l}-152.2 \\
(-3.17)\end{array}$ & $\begin{array}{c}-218.4 \\
(-2.4) \\
\end{array}$ & $\begin{array}{c}-104.1 \\
(-3.2)\end{array}$ & $\begin{array}{c}8.8 \\
(14.5)\end{array}$ \\
\hline $\mathrm{a}_{1}$ & $\begin{array}{l}75.1 \\
(4.5) \\
\end{array}$ & $\ldots$ & $\ldots$ & $\cdots$ & $\cdots$ \\
\hline$a_{2}$ & $\ldots$ & $\begin{array}{c}0.28 \\
(2.34) \\
\end{array}$ & $\begin{array}{c}0.4 \\
(2.4) \\
\end{array}$ & $\begin{array}{c}0.4 \\
(3.8) \\
\end{array}$ & $\begin{array}{c}0.3 \\
(2.7) \\
\end{array}$ \\
\hline $\mathrm{b}$ & $\cdots$ & $\begin{array}{c}0.08 \\
(3.35)\end{array}$ & $\begin{array}{c}0.1 \\
(2.5)\end{array}$ & $\begin{array}{c}0.1 \\
(3.4)\end{array}$ & $\ldots$ \\
\hline $\mathrm{R}^{2}$ & 0.50 & 0.50 & 0.63 & 0.63 & 0.55 \\
\hline
\end{tabular}

Заключение. Таким образом, в данной работе были рассмотрены модели промышленных роботов для выполнения наиболее распространенных операций. Получено, что цена промышленных роботов компаний Kuka, Yaskawa Motoman и Fanuc для различных операций растет с увеличением технического индекса и года выпуска модели. Также выявлена положительная корреляция между ценой роботов и их грузоподъемностью для покрасочных роботов Kuka.

\section{СПИСОК ЛИТЕРАТУРЫ}

1. Комкина Т.А., Никонова М.А., Дубинина М.Г. Технико-экономический анализ отдельных видов сервисных роботов // Экономический анализ: теория и практика. 2020. Т.19, вып.10. С. 1965-1986.

DOI: https://doi.org/10.24891/ea.19.10.1965. 
2. Варшавский А.Е., Дубинина В.В. Основные тенденции изменения техникоэкономических показателей промышленных роботов // Национальные интересы: приоритеты и безопасность. - 2018. - Т. 14, № 10. - С. 1916 - 1935. https://doi.org/10.24891/ni.14.10.1916

3. Цифры про роботов. Отчет IFR и HAУPP о рынке робототехники. URL: https://ritm-magazine.ru/ru/video/cifry-pro-robotov-otchet-ifr-i-naurr-o-rynkerobototehniki.html

4. Использование промышленных роботов: обзор рынка робототехники в России и мире. URL: https://delprof.ru/upload/iblock/987/DelProf_Analitika_Rynok-robototekhniki.pdf

5. НАУРР. Аналитическое исследование: Мировой рынок робототехники. URL: http://robotforum.ru/assets/files/000_News/NAURR-Analiticheskoeissledovanie-mirovogo-rinka-robototehniki-(yanvar-2016).pdf

6. Сбербанк. Аналитический обзор мирового рынка робототехники 2019. URL: https://adindex.ru/files2/access/2019_07/273895_sberbank_robotics_review_2019_17.07.2019_m.pdf

7. Производственные роботы-манипуляторы KUKA - немецкое качество. URL: https://vektorus.ru/blog/obzory/robot-manipulyator-kuka.html

8. ГАЗ. Роботизация производственных площадок. URL: https://gazgroup.ru/technology/robots/

9. Промышленные роботы Kuka. URL: https://www.kuka.com/ru-ru/продукцияуслуги/промышленная-робототехника/промышленные-роботы

10. Промышленные роботы Fanuc. URL: https://www.fanuc.eu/ru/ru/poботы 11. Роботы Motoman. URL: https://ru.yaskawa.eu.com/products/robots

\section{ANALYSIS OF TECHNICAL AND ECONOMIC INDICATORS OF INDUSTRIAL ROBOTS}

\section{Dubinina V.V.}

This paper presents the analysis of technical and economic indicators of industrial robots for painting, spot welding and palletizing by Kuka, Fanuc and Yaskawa Motoman. For these robots, the models of the dependencies of the price on the payload, reach, repeatability, robot weight and technical index are developed. 